\title{
ẢNH HƯởNG CỦA CÁC YẾU TỐ CHẤT LƯợNG CUỘC SỐNG NƠI LÀM VIỆC ĐẾN SỬ GẤN KẾT VỚI TỔ CHỨC CỦA NHÂN VIÊNN NGÂN HÀNG THƯƠNG MẠI CỔ PHẦN Á CHÂU TẠI TP. HCM
}

Bùi Nhất Vương*

\section{TÓM TĂT}

Nghiên cứu kiểm định các yếu tố Chất lượng cuộc sống nơ làm việc ảnh hưởng đến sự gắn kết của nhân viên ngân hàng thương mại cổ phần Á Châu tại TPHCM, bằng việc khảo sát 230 nhân viên. Phwơng pháp phân tích Cronbach's Alpha, phân tích EFA cùng với phân tích hồi quy bội được sủ dụng với phần mềm SPSS. Kết quả cho thấy múc độ ảnh huởng của các yếu tố - theo tầm quan trọng giảm dần- đến Sự gắn kết nhân viên gồm: Co hội phát triển nghề nghiệp, Phát triển năng lục cá nhân, Cân bằng giữa công việc và cuộc sống, Luơng thương công bằng và tương xưng, Hội nhập trong tổ chức, Quy tắc trong tổ chúc. Nghiên cưu đề ra một số hàm ý quản trị đến các nhà quản lý ngân hàng thwơng mại cổ phần Á Châu tại TPHCM nhằm tăng cương sụ gắn kết của nhân viên.

Tù̀ khóa: Chất luộng cuộc sống nơi làm việc, Sụ gắn kết của nhân viên, Co hội phát triển nghề nghiệp, Phát triển năng lục cá nhân, Cân bằng giữa công việc và cuộc sống, Lương thường công bằng và tương xứng, Hội nhập trong tổ chức, Quy tắc trong tổ chức.

\section{THE INFLUENCE OF QUALITY OF WORKING LIFE ON THE EMPLOYEE COMMITMENT IN ACB BANK HCMC}

\begin{abstract}
The objective of this research is to examine how the factors of Quality of working life influence on employee commitment at Asia Commercial Bank by interviewing 230 staffs who working in Ho Chi Minh City. The method of Cronbach's Alpha analysis, EFA analysis, and multiple regression analysis were used with the SPSS software. The result showed that six aspects of Quality of working life impact on employee commitment decreasingly: Career opportunity; Personal capacity development; Work-life balance; Fair remuneration; Organizational integration; Organizational rules. The study also suggested bank managers should improve employee's quality of working life which lead to enhance their commitment to the organization.
\end{abstract}

Keywords: Quality of working life, Career opportunity; Personal capacity development; Work-life balance; Fair remuneration; Organizational integration; Organizational rules

\section{Giới thiệu}

Chất lượng cuộc sống nơi làm việc (Quality of working life - QWL) là một khái niệm mặc dù ra đời hơn ba thập kỷ qua nhưng vẫn còn là một khái niệm mới mẻ, thú vị, thu hút được sự quan tâm của các nhà nghiên cứu (Martel và Dupuis, 2006). Các điều kiện của cuộc sống ngày càng gia tăng, nhân viên luôn băn khoăn xem xét công việc của mình có mang lại niềm vui và ý nghĩa hay không? Không chỉ dừng lại ở các chế độ lương thưởng, phúc lợi, đào tạo mà nhân viên còn làm việc với những mối quan hệ trong công việc những yếu tố về môi trường làm việc mà công ty cung cấp, hoặc sự cân bằng giữa công việc và cuộc sống hằng ngày. Chính những

\footnotetext{
* ThS, Trường Đại học Ngoại ngữ- Tin học TP.HCM
} 
yếu tố này góp phần hình thành ở nhân viên lòng nhiệt tình, niềm đam mê công việc và sự gắn kết lâu dài với tổ chức.

Sau một thời gian phát triển, nhằm để thích ứng kịp thời với những thay đổi của môi trường kinh doanh, ngân hàng $\mathrm{ACB}$ đã và đang tiến hành tái cấu trúc toàn diện. Quá trình tái cơ cấu tổ chức, sự thay đổi của bộ máy hoạt động, cách thức làm việc, môi trường làm việc, đã dẫn đến sự thay đổi đáng kể về mặt nhân sự. Trong năm 2015 và năm 2016 , tỷ lệ nhân viên thôi việc $13.26 \%$, và việc tuyển dụng bổ sung một số lượng lớn nhân viên làm cho ngân hàng $\mathrm{ACB}$ tốn nhiều chi phí, thời gian, công sức đào tạo, tuyển dụng. Việc nghiên cứu Chất lượng cuộc sống nơi làm việc tại $\mathrm{ACB}$, để từ đó xác định ảnh hưởng đến sự gắn kết với tổ chức của nhân viên là rất cần thiết.

\section{Cơ sở lý thuyết}

\section{Khái niệm về Chất lượng cuộc sống nơi làm việc}

Chất lượng cuộc sống nơi làm việc là một khái niệm phức tạp, đa chiều và trừu tượng (Hsu và Kernohan, 2006). Theo Robbins (1989) chất lượng cuộc sống nơi làm việc là một quá trình mà tổ chức đáp ứng các nhu cầu của người lao động bằng cách phát triển các cơ chế tạo điều kiện cho người lao động có

\section{Bảng 1. Tổng hợp các thành phần Chất lượng cuộc sống nơi làm việc}

\begin{tabular}{|l|l|}
\hline Tác giả nghiên cứu & \multicolumn{1}{c|}{ Các thành phần của QWL } \\
\hline \multirow{5}{*}{ Walton (1974) } & Lương thưởng công bằng và tương xứng \\
& Điều kiện làm việc an toàn và khỏe mạnh \\
& Phát triển năng lực cá nhân \\
& Cơ hội phát triển nghề nghiệp và sự đảm bảo công việc \\
& Hội nhập xã hội trong tổ chức \\
& Quy tắc trong tổ chức \\
& Cân bằng công việc và cuộc sống cá nhân \\
& Mối liên quan xã hội của công việc \\
\hline \multirow{5}{*}{ Levine, Taylor và Davis (1984) } & Sự tôn trọng và tin tưởng vào khả năng cấp trên \\
& Sự thay đổi trong công việc \\
& Thách thức trong công việc \\
& Cơ hội phát triển nghề nghiệp \\
& Lòng tự trọng \\
& Sự ảnh hưởng của công việc và cuộc sống ngoài công việc \\
\hline
\end{tabular}




\begin{tabular}{|c|c|}
\hline & Sự đóng góp cho xã hội của công việc \\
\hline Lau và Bruce (1998) & $\begin{array}{l}\text { Sự đảm bảo công việc } \\
\text { Hệ thống khen thưởng } \\
\text { Đào tạo } \\
\text { Các cơ hội phát triển } \\
\text { Sự tham gia vào quá trình ra quyết định }\end{array}$ \\
\hline Arts, Kerksta và Zee (2001) & $\begin{array}{l}\text { Lương thưởng công bằng và tương xứng } \\
\text { Điều kiện làm việc an toàn và khỏe mạnh } \\
\text { Mối liên quan xã hội của công việc } \\
\text { Áp lực trong công việc }\end{array}$ \\
\hline Rose và cộng sự (2006) & $\begin{array}{l}\text { Sự thõa mãn công việc } \\
\text { Thành tựu trong công việc } \\
\text { Sự cân bằng trong công việc }\end{array}$ \\
\hline Ouppara và Sy (2012) & $\begin{array}{l}\text { Lương thưởng công bằng và tương xứng } \\
\text { Điều kiện làm việc an toàn và khỏe mạnh } \\
\text { Phát triển năng lực cá nhân } \\
\text { Cơ hội phát triển nghề nghiệp và sự đảm bảo công việc } \\
\text { Hội nhập xã hội trong tổ chức }\end{array}$ \\
\hline Asgari, Nojbaee, Rahnama (2012) & $\begin{array}{l}\text { Lương thưởng công bằng và tương xứng } \\
\text { Điều kiện làm việc an toàn } \\
\text { Phát triển năng lực cá nhân và khỏe mạnh } \\
\text { Cơ hội phát triển nghề nghiệp và sự đảm bảo công việc } \\
\text { Hội nhập xã hội trong tổ chức } \\
\text { Quy tắc trong tổ chức } \\
\text { Cân bằng công việc và cuộc sống cá nhân } \\
\text { Mối liên quan xã hội của công việc }\end{array}$ \\
\hline
\end{tabular}

Tác giả chọn mô hình của Walton (1974) làm nền tảng để thực hiện nghiên cứu tại ngân hàng $\mathrm{ACB}$ tại $\mathrm{TPHCM}$, vì các thành phần chất lượng cuộc sống nơi làm việc của Walton đã được sử dụng nhiều trong các nghiên cứu và hàm chứa các thành phần của các tác giả khác. Đặc biệt, mô hình QWL đã được Asgari, Dadashi (2011) sử dụng để nghiên cứu trong lĩnh vực ngân hàng tại Iran, một quốc gia Châu Á.

\section{Khái niệm về sự gắn kết với tổ chức}

Theo Bateman (1984), gắn kết với tổ chức là mối quan hệ đa chiều trong tự nhiên, liên quan đến lòng trung thành của nhân viên cho tổ chức, sẵn sàng nỗ lực cho tổ chức, mức độ mục tiêu và giá trị hợp thức với tổ chức, và mong muốn duy trì với tổ chức. Sự gắn kết tổ chức là sức mạnh của sự đồng nhất của cá nhân với tổ chức và sự tham gia tích cực trong
Nguồn: Tóm tắt của tác giả tổ chức; những nhân viên có sự gắn kết với tổ chức ở mức độ cao sẽ hài lòng hơn với công việc của họ, sẽ rất ít khi rời bỏ công việc và gắn bó với tổ chức hơn (Mowday và cộng sự, 1979).

Ilies \& Judge (2003) định nghĩa: "Sự gắn kết là sự sẵn sàng nỗ lực hết mình vì sự phát triển của tổ chức, đồng nhất mục tiêu của tổ chức với mục tiêu của chính mình".

\section{Các thành phần của sự gắn kết của nhân viên với tổ chức}

Đã có nhiều công trình nghiên cứu về sự gắn kết của nhân viên với tổ chức (bảng 2).

Định nghĩa của Meyer và Allen (1991) được chấp nhận và sử dụng nhiều nhất trong các nghiên cứu hiện nay, có ba dạng gắn bó "tình cảm", "bắt buộc" và "quy chuẩn", 
nghiên cứu này chỉ chọn thành phần gắn bó

tình cảm làm biến phụ thuộc.

Bảng 2. Các quan điểm đo lường ý thức gắn kết đối với tổ chức

\begin{tabular}{|c|c|}
\hline Tác giả & Thang do \\
\hline $\begin{array}{l}\text { Mowday, Porter \& } \\
\text { Steer (1979) }\end{array}$ & $\begin{array}{l}\text { Sư đồng thuận (Identification): mục tiêu cá nhân trùng với mục tiêu tổ chức, } \\
\text { có niềm tin mạnh mẽ và chấp nhận mục tiêu và giá trị của tổ chức. } \\
\text { Lòng trung thành (Loyalty): mong muốn một cách mạnh mẽ duy trì vai trò } \\
\text { thành viên của tổ chức. } \\
\text { Sụ lôi cuốn (Involvement): bị lôi cuốn vào các hoạt động của tổ chức và } \\
\text { luôn cố gắng tự nguyện vì tổ chức. }\end{array}$ \\
\hline Angle \& Perry (1981) & $\begin{array}{l}\text { Gắn bó giá trị (Value commitment): Sự gắn kết để phục vụ cho mục tiêu của } \\
\text { tổ chức. } \\
\text { Gắn bó duy trì (Commitment to stay): Sự cam kết để duy trì vai trò thành } \\
\text { viên của họ trong tổ chức. }\end{array}$ \\
\hline $\begin{array}{l}\text { O'reilly \& Chatman } \\
\qquad(1986)\end{array}$ & $\begin{array}{l}\text { Sư tuân thủ (Compliance): sự lôi cuốn vì những phần thưởng đặc biệt } \\
\text { Sụ đồng thuận (Identification): sự gắn kết vì mong muốn hội nhập với tổ } \\
\text { chức. } \\
\text { Sụ tiếp thu (Internalisation): sự lôi cuốn do có sự phù hợp, sự tương đồng } \\
\text { giữa giá trị của cá nhân với giá trị của tổ chức. }\end{array}$ \\
\hline $\begin{array}{l}\text { Penley \& Gould } \\
\text { (1988) }\end{array}$ & $\begin{array}{l}\text { Đạo đúc (Moral): Sự chấp nhận và đồng thuận với mục tiêu của tổ chức. } \\
\text { Tính toán (Calculative): Sự đồng thuận với tổ chức vì nhân viên cảm thấy } \\
\text { hài lòng với sự khích lệ vật chất khi có những đóng góp cho tổ chức. } \\
\text { Thờ o (Alienative): Nhân viên ở lại tổ chức chỉ vì áp lực của môi trường, dù } \\
\text { họ nhận thấy những gì họ nhận được không còn tương xứng với công sức. }\end{array}$ \\
\hline $\begin{array}{l}\text { Meyer \& Allen } \\
\text { (1991) }\end{array}$ & $\begin{array}{l}\text { Gắn kết tình cảm (Affective Commitment): Tình cảm gắn bó, đồng thuận và } \\
\text { bị lôi cuốn vào trong tổ chức. } \\
\text { Gắn kết bắt buộc (Continuance Commitment): gắn bó do người nhân viên } \\
\text { nhận thấy chi phí phải trả cao (chi phí cơ hội) khi phải rời bỏ tổ chức. } \\
\text { Gắn kết quy chuẩn (Normative Commitment): Cảm giác có nghĩa vụ tiếp } \\
\text { tục công việc. }\end{array}$ \\
\hline $\begin{array}{c}\text { Mayer \& Schoorman } \\
\qquad(1992)\end{array}$ & $\begin{array}{l}\text { Giá trị (Value): Niềm tin và sự chấp nhận các mục tiêu và giá trị của tổ chức } \\
\text { và sự sẵn sàng nỗ lực cho tổ chức. } \\
\text { Sụ duy trì (continuance): Mong muốn duy trì vai trò thành viên của tổ chức. }\end{array}$ \\
\hline $\begin{array}{c}\text { Jaros và cộng sự } \\
\text { (1993) }\end{array}$ & $\begin{array}{l}\text { Yêu mến (Affective): mức độ mà một cá nhân gắn bó về mặt tâm lý với tổ } \\
\text { chức thông qua những cảm giác như lòng trung thành, cảm thấy yêu mến tồ } \\
\text { chức, nhiệt tình vì tổ chức, hài lòng và cảm thấy mình thuộc về tổ chức. } \\
\text { Sứ duy trì (Continuance): mức độ mà cá nhân cảm thấy phải gắn bó với tổ } \\
\text { chức bởi vì họ phải mất mát quá nhiều thứ nếu rời bỏ tổ chức. } \\
\text { Đạo đức (Moral): Mức độ mà cá nhân gắn bó về mặt tâm lý với tổ chức } \\
\text { thông qua việc tiếp thu mục tiêu, giá trị và sứ mạng của tổ chức. }\end{array}$ \\
\hline
\end{tabular}


Mối liên hệ giữa chất lượng cuộc sống nơi làm việc và sự gắn kết nhân viên với tổ chức

Hầu hết các nghiên cứu chất lượng cuộc sống nơi làm việc đều chỉ ra mối liên kết giữa chất lượng cuộc sống nơi làm việc với các kết quả liên quan đến công việc. Kết quả nghiên cứu của Huang, Lawer và Lei (2007) kết luận rằng chất lượng cuộc sống nơi làm việc có ảnh hưởng đáng kể đến sự gắn kết với tổ chức.

Nghiên cứu của Kalayanee (2007) về mối liên hệ giữa $Q W L$ và kết quả liên quan đến công việc: sự hài lòng công việc, sự gắn kết với tổ chức và tinh thần đồng đội; khảo sát các nhà quản lý Marketing và quản lý nhân sự tại 514 doanh nghiệp niêm yết trên thị trường chứng khoán Thái Lan, cho thấy QWL có sự tác động mạnh mẽ đến sự gắn kết với tổ chức. Nghiên cứu của Daud (2010) khảo sát mối liên hệ giữa $\mathrm{QWL}$ và sự gắn kết với tổ chức của nhân viên tại các doanh nghiệp Malaysia, cho thấy các thành phần của QWL là lương thưởng, liên hệ xã hội, sử dụng năng lực cá nhân và phát triển nghề nghiệp tác động dương đến thành phần gắn kết tự nguyện của nhân viên.

\section{Mô hình nghiên cứu được đề xuất}

Nghiên cứu này lựa chọn mô hình dựa trên cơ sở Chất lượng cuộc sống trong công việc của Walton (1974), Asgari, Dadashi (2011), Asgari, Nojbaee, Rahnama (2012), và sau đó tác giả đã tiến hành nghiên cứu định tính, hiệu chỉnh mô hình. Mô hình nghiên cứu được tác giả đề xuất nghiên cứu tại công ngân hàng TMCP $\mathrm{ACB}$ TPHCM với tám thành phần: Điều kiện làm việc an toàn; Cơ hội phát triển nghề nghiệp; Quy tắc trong tổ chức; Cân bằng trong cuộc sống công việc; Liên quan xã hội của công việc; Lương thưởng công bằng và tương xứng; Phát triển năng lực cá nhân và Hòa nhập trong tổ chức. (Hình 1)

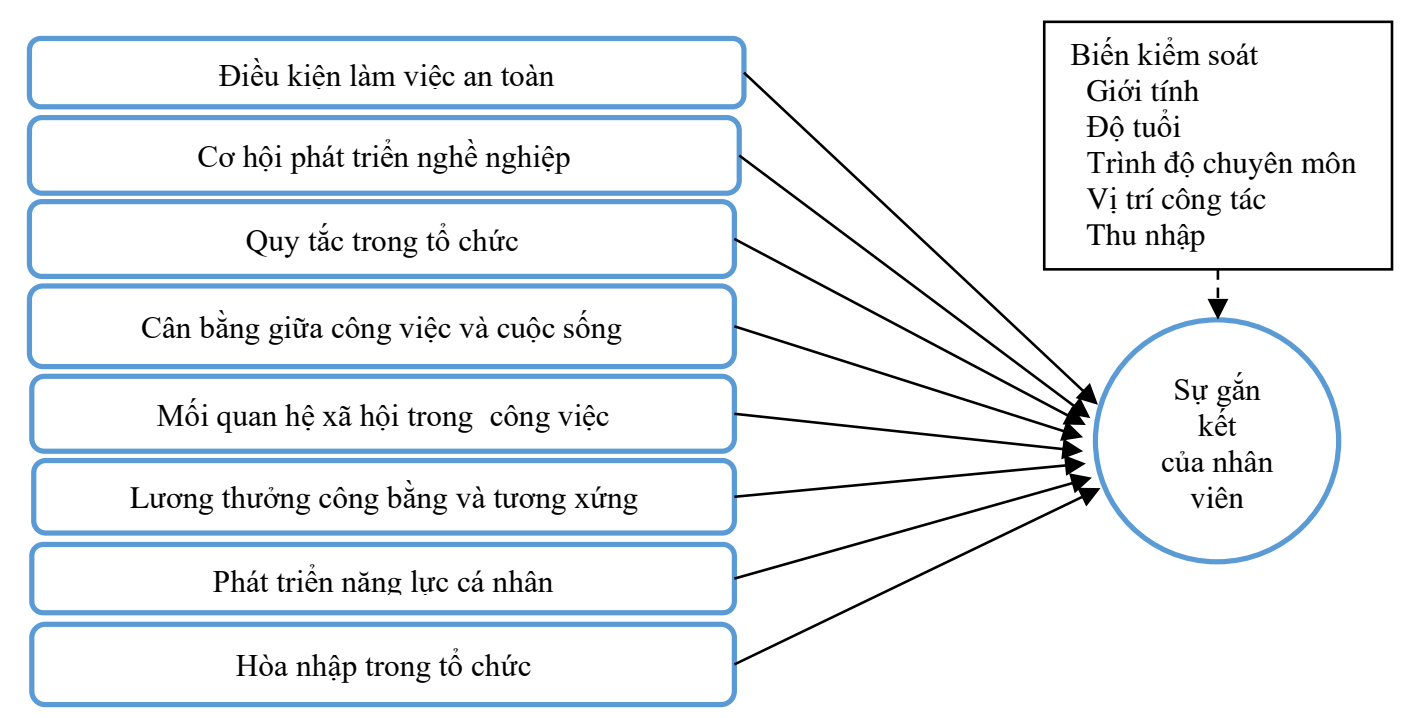

Hình 1. Mô hình nghiên cứu được đề xuất của tác giả

Nguồn: tác giả nghiên cưu

$H_{1}$ : Điều kiện làm việc an toàn có quan hệ cùng chiều với sự gắn kết nhân viên với tổ chức.

$H_{2}$ : Cơ hội phát triển nghề nghiệp có quan hệ cùng chiều với sự gắn kết nhân viên với tổ chức.

$H_{3}$ : Quy tắc trong tổ chức có quan hệ cùng chiều với sụ gắn kết nhân viên với tổ chức.

$H_{4}$ : Cân bằng công việc và cuộc sống có quan hệ cùng chiều với sự gắn kết nhân viên với tổ chức.

$H_{5}$ : Mối quan hệxã hội trong công việc có quan hệ cùng chiều với sự gắn kết nhân viên với tổ chức. 
$H_{6}$ : Lương thưởng công bằng và tương xứng có quan hệ cùng chiều với sự gắn kết nhân viên với tổ chuic.

H7: Phát triển năng lực cá nhân có quan hệ cùng chiều với sự gắn kết nhân viên với tổ chức.

H: Hội nhập trong tổ chức có quan hệ cùng chiều với sự gắn kết nhân viên với tổ chức.

\section{Kết quả nghiên cứu}

\section{Mô tả dữ liệu}

Số bảng khảo sát được gởi đi là 234 bảng, đối tượng là nhân viên ngân hàng $\mathrm{ACB}$ tại Tp. HCM, thu về được 234 bảng, sau khi loại bỏ các phiếu trả lời không đạt yêu cầu, còn lại là 230 bảng, đạt tỷ lệ $98.29 \%$. Kết quả khảo sát nữ chiếm 43\%, nam 57\%; độ tuối 26-35 tuổi chiếm $44.3 \%$, từ $18-25$ chiếm $37.8 \%, 36-45$ chiếm $14.8 \%$, trên 45 chiếm $3.0 \%$; trình độ sau đại học chiếm $5.0 \%$; trình độ đại học chiếm $45 \%$, cao đẳng $38 \%$, trung cấp trở xuống $12 \%$; số nhân viên có mức thu nhập hàng tháng từ 5 đến 10 triệu đồng chiếm $56.1 \%$, trên $10-15$ triệu đồng $20.9 \%$ dưới 5 triệu đồng $14.8 \%$, trên 15 triệu đồng 8.3\%; những người làm việc từ dưới 2 năm chiếm $45.2 \%$, từ 3-5 năm chiếm tỉ lệ $31.3 \%$, từ 6-10 năm chiếm tỉ lệ $19.6 \%$ và nhân viên có thời gian công tác trên 10 năm chiếm tỷ lệ $3.9 \%$, nhân viên chiếm $92 \%$, quản lý chiếm $8 \%$.

\section{Đánh giá độ tin cậy của thang đo bằng Cronbach's Alpha}

Sau khi phân tích Cronbach's Alpha lần 1, các biến bị loại: DTPT3, CVCS3 do có tương quan với biến tổng nhỏ hơn 0.3 . Kết quả kiểm định lần 2 , các thang đo trên đều có hệ số Cronbach Alpha khá cao $(>0.7)$, hệ số tương quan biến- tổng lớn hơn 0,3 (bảng 3 ), do đó, được sử dụng cho phân tích EFA tiếp theo.

Bảng 3. Kết quả phân tích Cronbach's alpha và tương quan biến- tổng

\begin{tabular}{|l|c|r|r|}
\hline \multicolumn{1}{|c|}{ Thang đo } & $\begin{array}{c}\text { Số biến } \\
\text { quan sát }\end{array}$ & $\begin{array}{c}\text { Cronbach's } \\
\text { Alpha }\end{array}$ & $\begin{array}{c}\text { Hệ số } \\
\text { tương quan biến- } \\
\text { tổng nhỏ nhất }\end{array}$ \\
\hline Điều kiện làm việc an toàn & 5 & 0.838 & 0.552 \\
\hline Cơ hội phát triển nghề nghiệp & 4 & 0.765 & 0.475 \\
\hline Quy tắc trong tổ chức & 5 & 0.816 & 0.521 \\
\hline Cân bằng giữa công việc và cuộc sống & 4 & 0.796 & 0.422 \\
\hline Mối quan hệ xã hội trong công việc & 5 & 0.848 & 0.533 \\
\hline Lương thưởng công bằng và tương xứng & 4 & 0.895 & 0.530 \\
\hline Phát triển năng lực cá nhân & 5 & 0.804 & 0.561 \\
\hline Hội nhập trong tồ chức & 5 & 0.809 & 0.542 \\
\hline Sự gắn kết của nhân viên với tổ chức & 5 & 0.836 & \\
\hline
\end{tabular}

Nguồn: Kết quả phân tích của tác giả

\section{Phân tích nhân tố khám phá EFA}

Kiểm định Bartlett's trong phân tích nhân tố cho thấy sig $=0.000$; hệ số KMO là
0.836 (giữa 0.5 và 1 ), các biến quan sát trong tổng thể có mối tương quan với nhau và phân tích nhân tố (EFA) là thích hợp. 
Bảng 4. Kết quả EFA thang đo các thành phần chất lượng cuộc sống nơi làm việc

\begin{tabular}{|c|c|c|c|c|c|c|c|c|}
\hline \multirow{2}{*}{ Biến quan sát } & \multicolumn{8}{|c|}{ Hệ số tải nhân tố } \\
\hline & 1 & 2 & 3 & 4 & 5 & 6 & 7 & 8 \\
\hline QHXH4 & .792 & & & & & & & \\
\hline QHXH3 & .736 & & & & & & & \\
\hline QHXH5 & .729 & & & & & & & \\
\hline QHXH2 & .724 & & & & & & & \\
\hline QHXH1 & .634 & & & & & & & \\
\hline LTCB1 & & .870 & & & & & & \\
\hline LTCB4 & & .865 & & & & & & \\
\hline LTCB3 & & .856 & & & & & & \\
\hline LTCB2 & & .825 & & & & & & \\
\hline QTTC5 & & & .785 & & & & & \\
\hline QTTC1 & & & .731 & & & & & \\
\hline QTTC4 & & & .694 & & & & & \\
\hline QTTC3 & & & .666 & & & & & \\
\hline QTTC2 & & & .640 & & & & & \\
\hline DKLV2 & & & & .773 & & & & \\
\hline DKLV5 & & & & .750 & & & & \\
\hline DKLV3 & & & & .694 & & & & \\
\hline DKLV4 & & & & .686 & & & & \\
\hline DKLV1 & & & & .519 & & & & \\
\hline NLCN2 & & & & & .802 & & & \\
\hline NLCN4 & & & & & .781 & & & \\
\hline NLCN1 & & & & & .778 & & & \\
\hline NLCN5 & & & & & .737 & & & \\
\hline NLCN3 & & & & & .650 & & & \\
\hline HNTC1 & & & & & & .776 & & \\
\hline HNTC5 & & & & & & .761 & & \\
\hline HNTC3 & & & & & & .744 & & \\
\hline HNTC4 & & & & & & .742 & & \\
\hline HNTC2 & & & & & & .723 & & \\
\hline DTPT4 & & & & & & & .849 & \\
\hline DTPT2 & & & & & & & .818 & \\
\hline DTPT5 & & & & & & & .698 & \\
\hline DTPT1 & & & & & & & .674 & \\
\hline CVCS1 & & & & & & & & .838 \\
\hline CVCS4 & & & & & & & & .749 \\
\hline CVCS2 & & & & & & & & .682 \\
\hline CVCS5 & & & & & & & & .576 \\
\hline Eigenvalue & 7.596 & 4.122 & 2.888 & 2.48 & 2.203 & 1.689 & 1.515 & $\mathbf{1 . 3 5 9}$ \\
\hline $\begin{array}{l}\text { Phương sai trích } \\
\text { tích lũy }(\%)\end{array}$ & 20.53 & 31.67 & 39.476 & 46.178 & 52.133 & 56.698 & 60.793 & 64.465 \\
\hline
\end{tabular}

Nguồn: Kết quả phân tích của tác giả

Kết quả phân tích EFA, với phương pháp quan sát và phương sai trích tích lũy $66.465 \%$ trích nhân tố principal component và phép (đạt yêu cầu $>50 \%$ ) (Bảng 4 ).

quay Varimax, trích được 8 nhân tố từ 37 biến 
Bảng 5. Kết quả EFA thang đo sự gắn kết của nhân viên với tổ chức

\begin{tabular}{|l|r|}
\hline \multicolumn{1}{|c|}{ Biến quan sát } & \multicolumn{1}{|c|}{ Hệ số tải nhân tố } \\
\hline GK5 & .846 \\
\hline GK2 & .817 \\
\hline GK1 & .772 \\
\hline GK3 & .751 \\
\hline GK4 & .691 \\
\hline Eigenvalue & $\mathbf{3 . 0 2 2}$ \\
\hline Phương sai trích tích lũy (\%) & $\mathbf{6 0 . 4 3 6}$ \\
\hline
\end{tabular}

Nguồn: Kết quả phân tích của tác giả

Phân tích nhân tố thang đo sự gắn kết của nhân viên với tổ chức, kiểm định Barlett có $\operatorname{sig}=0.000, \mathrm{KMO}=0.740$ (giữa 0.5 và 1 ), các biến qua sát trong tổng thể có mối tương quan với nhau và phân tích nhân tố (EFA) là thích hợp.

\section{Phân tích tương quan}

Ma trận tương quan cho thấy mức ý nghĩa của các hệ số rất nhỏ $(\operatorname{sig}=0<0.05)$
Phân tích EFA với phương pháp trích nhân tố principal component, phép quay Varimax, trích được một nhân tố với 5 biến quan sát và phương sai trích tích lũy được là $60.436 \%$ (>50\%), đạt yêu cầu (Bảng 5).

nên các hệ số tương quan có ý nghĩa thống kê và đều đủ điều kiện để đưa vào phân tích hồi quy.

\section{Phân tích hồi quy tuyến tính}

Bảng 6. Thống kê phân tích các hệ số hồi quy

\begin{tabular}{|c|c|c|c|c|c|c|c|c|}
\hline \multirow{2}{*}{\multicolumn{2}{|c|}{ Mô hình }} & \multicolumn{2}{|c|}{$\begin{array}{l}\text { Hệ số chưa chuẩn } \\
\text { hóa }\end{array}$} & \multirow{3}{*}{$\begin{array}{l}\begin{array}{l}\text { Hệ số } \\
\text { chuẩn hóa }\end{array} \\
\text { Beta } \\
\end{array}$} & \multirow{3}{*}{$\begin{array}{l}\mathbf{t} \\
1.804 \\
\end{array}$} & \multirow{3}{*}{$\begin{array}{l}\text { Sig. } \\
.073 \\
\end{array}$} & \multicolumn{2}{|c|}{$\begin{array}{l}\text { Thống kê } \\
\text { đa cộng tuyến }\end{array}$} \\
\hline & & \multirow{2}{*}{$\begin{array}{l}\text { B } \\
.535\end{array}$} & \multirow{2}{*}{\begin{tabular}{|l|}
$\begin{array}{l}\text { Sai số } \\
\text { chuẩn }\end{array}$ \\
.296 \\
\end{tabular}} & & & & & \\
\hline \multirow{13}{*}{1} & (Hằng số) & & & & & & & \\
\hline & DKLV & .055 & .039 & .067 & 1.402 & .162 & .978 & 1.022 \\
\hline & DTPT & .310 & .029 & .527 & 10.781 & .000 & .930 & 1.076 \\
\hline & QTTC & .101 & .043 & .155 & 2.346 & .020 & .510 & 1.962 \\
\hline & CVCS & .169 & .039 & .217 & 4.326 & .000 & .879 & 1.137 \\
\hline & QHXH & .041 & .034 & .068 & 1.221 & .223 & .722 & 1.385 \\
\hline & LTCB & .163 & .038 & .206 & 4.294 & .000 & .961 & 1.041 \\
\hline & NLCN & .211 & .033 & .368 & 6.434 & .000 & .678 & 1.476 \\
\hline & HNTC & .192 & .083 & .157 & 2.299 & .022 & .490 & 2.041 \\
\hline & \multicolumn{8}{|c|}{$R^{2}$ hiệu chỉnh: 0.734} \\
\hline & \multicolumn{8}{|c|}{ Thống kê F (ANOVA): 28.758} \\
\hline & \multicolumn{8}{|c|}{ Mức ý nghĩa (Sig. của ANOVA): 0.000 } \\
\hline & \multicolumn{8}{|c|}{ Durbin-Watson: 2.026} \\
\hline
\end{tabular}

Nguồn: Kết quả phân tích của tác giả

Trị thống kê $\mathrm{F}=28.758$ với giá trị sig $=$ 0.000 chứng tỏ mô hình hồi quy phù hợp với tập dữ liệu. Durbin-Watson là $2.026<3$ không có sự tương quan giữa các biến trong mô hình. Hệ số VIF của các biến đều có trị < 10 chứng tỏ không xảy ra hiện tượng đa cộng 
tuyến. Hệ số $\mathrm{R}^{2}$ hiệu chỉnh 0.734 cho thấy $73.4 \%$ sự biến thiên của biến phụ thuộc được giải thích bởi các biến độc lập. Biến Điều kiện làm việc an toàn và biến Mối quan hệ xã hội trong công việc bị loại (do sig.DKLV $=0.162>0.05$; sig. . $\mathrm{QH}$ ( $=0.223>0.05$ ). Phương trình hồi quy chưa chuẩn hóa có dạng: $\mathbf{G K}=0.535+0.310 *$ DTPT + $0.101 *$ QTTC $+0.169 *$ CVCS + $0.163 *$ LTCB $+\quad 0.211 *$ NLCN $+0.192 *$ HNTC.

Các hệ số hồi quy đều mang dấu dương (+) thể hiện các biến độc lập có quan hệ thuận với biến phụ thuộc. Sự gắn kết của nhân viên với tổ chức (GK) chịu tác động nhiều nhất và thấp dần theo thứ tự: Cơ hội phát triển nghề nghiệp $\left(\beta_{2}=0.527\right)$, Phát triển năng lực cá nhân ( $\left.\beta_{7}=0.368\right)$, Cân bằng giữa công việc và cuộc sống $\left(\beta_{4}=0.217\right)$, Lương thưởng công bằng và tương xứng $\left(\beta_{6}=\right.$ 0.206), Hội nhập trong tổ chức $\left(\beta_{8}=0.157\right)$

\section{Kết luận và đề xuất hàm ý quản trị}

\subsection{Kết luận}

Kết quả nghiên cứu cho thấy các yếu tố Chất lượng cuộc sống nơi làm việc ảnh hưởng đến sự gắn kết của nhân viên với tổ chức. Người lao động hiện tại gắn kết với ngân hàng ở mức độ trung bình (giá trị trung bình = 3.47). Toàn bộ thang đo được sử dụng trong nghiên cứu là đáng tin cậy (Cronbach's Alpha $>0.7$ ). Nghiên cứu chỉ ra rằng có 06 yếu tố QWL có quan hệ đồng biến đến sự gắn kết của nhân viên với ngân hàng, sắp xếp theo thứ tự giảm dần: Cơ hội phát triển nghề nghiệp, Phát triển năng lực cá nhân, Cân bằng giữa công việc và cuộc sống, Lương thưởng công bằng và tương xứng, Hội nhập trong tổ chức, Quy tắc trong tổ chức.

\section{2. Đề xuất hàm ý quản trị}

\section{Cơ hội phát triển nghề nghiệp}

"Cơ hội phát triển nghề nghiệp" có mức độ ảnh hưởng mạnh nhất đến sự gẳn kết của nhân viên. Để nâng cao sự gắn kết của nhân viên thông qua yếu tố cơ hội phát triển nghề nghiệp, ngân hàng cần phải thực hiện các hàm và Quy tắc trong tổ chức $\left(\beta_{3}=0.155\right)$ (Bảng 6). hồi quy

Kiểm định sự vi phạm của các giả định

Biểu đồ tần số của phần dư chuẩn hóa cho thấy phân phối chuẩn của phần dư xấp xỉ chuẩn 2.47E-15 (gần bằng 0 ) và độ lệch chuẩn $=0.982$ (gần bằng 1 ), giả thuyết phân phối chuẩn của phần dư không bị sai phạm. Biểu đồ tần số P-P cho thấy các điểm của phần dư phân tán phân tán ngẫu nhiên xung quanh đường chéo (đường thẳng kỳ vọng), giả định về phân phối chuẩn của phần dư được thỏa mãn. Đồ thị phân tán có sự phân tán đều, giả định phương sai không đổi của mô hình hồi quy không bị vi phạm. Qua các kết quả kiểm định trên cho thấy các giả định của hàm hồi quy tuyến tính không bị vi phạm và mô hình hồi quy đã xây dựng là phù hợp với tổng thể.

ý sau: Cần tạo nhiều cơ hội thăng tiến cho nhân viên, có chính sách thăng tiến rõ ràng, không thiên vị để tạo động lực cho người lao động phấn đấu. Nhà quản trị nên chú trọng đến các khóa đào tạo của doanh nghiệp, điều này không những giúp người lao động có điều kiện trau dồi kiến thức, kỹ năng, phát triển thêm những kiến thức mới để phục vụ cho công việc; nó còn là yếu tố khiến người lao động cảm thấy được ban lãnh đạo quan tâm, tạo điều kiện và cơ hội để họ phát triển. Để các khóa đào tạo của ngân hàng đem lại hiệu quả tốt nhất, ngân hàng cần phải xác định nhu cầu đào tạo hợp lý, lập kế hoạch đào tạo và lựa chọn hình thức nội dung đào tạo phù hợp với nhu cầu thực tế của nhân viên và tình hình thực tế của ngân hàng sau đó mới tiến hành đào tạo và kiểm tra kết quả sau đào tạo. Hơn nữa, ngân hàng cũng nên có chính sách đền bù các khóa đào tạo hợp lý. Nếu như người lao động đã làm việc, cống hiến cho ngân hàng trong một thời gian tối thiểu nào đó hoặc mang lại thành tích gì cho ngân hàng thì không phải đền bù các khóa đòa tạo khi họ nghỉ việc; và chi phí đền bù cũng chỉ ở mức độ vừa phải, hợp lý. Điều này sẽ khiến người lao động không quá lo lắng về việc phải đền 
bù chi phí đào tạo khi nghỉ việc, khi đó họ sẽ hào hứng và tham gia các khóa học đầy đủ hơn.

\section{Phát triển năng lực cá nhân}

"Phát triển năng lực cá nhân" có mức độ ảnh hưởng thứ hai đến sự gắn kết của nhân viên. Năng lực cá nhân là khả năng mà con người có thể thực hiện một hành động nào đó, nó là yếu tố thuộc tính cá nhân giúp cá nhân có thể hoàn thành công việc. Thứ nhất, nhà quản trị cần nhận thức được khả năng, năng lực của người lao động ở mức độ nào, thuộc về nhóm lĩnh vực nào để giao việc chính xác nhằm hoàn thành công việc tốt nhất. Thư hai, nhà quản trị cần tạo điều kiện cho người lao động nâng cao kỹ năng, năng lực của bản thân thông qua đào tạo, bổ sung kiến thức, cơ hội để được rèn luyện, được sử dụng kiến thức và phát triển kỹ năng của mình. Người lao động cần được tự chủ thực hiện công việc theo cách tốt nhất của bản thân họ. Thư $b a$, nhà quản trị cần truyền tải cho người lao động hiểu được tầm quan trọng của công việc mà họ đang làm để người lao động hiểu được công việc của họ cũng như bản thân họ quan trọng đến thế nào. Thư tu, nhà quản trị nên khuyến khích nhân viên phát triển những kỹ năng mới bằng cách đào tạo, nâng cao nhận thức, khả năng tư duy, cho nhân viên có cơ hội tiếp xúc với công việc thực tiễn,...Việc này không những giúp người lao động nâng cao tay nghề, khả năng hiểu biết, khuyến khích, tạo động lực cho người lao động phát triển mà còn giúp ngân hàng tạo ra nguồn lao động dồi dào với nhiều kỹ năng phù hợp với sự đa dạng hóa của công việc.

\section{Cân bằng giữa công việc và cuộc sống}

"Cân bằng giữa công việc và cuộc sống" có mức độ ảnh hưởng thứ ba đến sự gắn kết của nhân viên. Cân bằng giữa công việc và cuộc sống cho nhân viên được xem là một yếu tố mang tính chiến lược trong lĩnh vực quản lý nhân sự tại các công sở trong thế kỷ 21 . Nếu không có điều này, sức khỏe và các mối quan hệ sẽ bị ảnh hưởng, mức độ căng thẳng tăng cao, và năng suất công việc sẽ chựng lại. Nhà quản trị cần giảm bớt sự gò bó về thời gian cho nhân viên mà vẫn đảm bảo năng suất làm việc của họ như giữ nguyên thời gian làm việc 8 giờ/ngày, nhưng thời gian bắt đầu và kết thúc có thể thay đồi sao cho phù hợp với giờ giấc của cả nhân viên và tổ chức. Thành lập câu lạc bộ thể dục thể thao tại đơn vị như mở các lớp tập Gym, Yoga... miễn phí dành cho nhân viên. Qua đó, các nhân viên có thể nâng cao sức khỏe về thể chất và tinh thần của mình.

\section{Lương thưởng công bằng và tương xứng}

"Lương thưởng công bằng và tương xứng" có mức độ ảnh hưởng thứ tư đến sự gắn kết của nhân viên. Lương thưởng là một yếu tố quan trọng trong việc thu hút và giữ chân nhân viên trong tổ chức. Mức lương phải đảm bảo đủ để trang trải những chi phí sinh hoạt tối thiểu của cuộc sống và phải tương xứng với năng lực của người lao động, phải công bằng giữa các nhân viên với nhau. Một là, nhà quản trị cần xây dựng chế độ lương thưởng công bằng và hợp lý, thực hiện phân tích và mô tả công việc, đánh giá công việc cuối năm; phân hạng nhóm chức danh, xây dựng thang bảng lương, phản ánh đúng mức độ trách nhiệm và độ phức tạp của công việc; đảm bảo tính công bằng trong nội bộ ngân hàng. Hai là, cần khảo sát mức lương của các ngân hàng khác trong cùng nghành, cùng lĩnh vực để đưa ra được mức thang lương hợp lý, cạnh tranh cho ngân hàng mình. $B a$ là, cần xây dựng chính sách tiền thưởng công bằng, minh bạch và công khai, để người lao động hiểu rõ được các khoản tiền thưởng của mình đến từ đâu và tương xứng với kết quả mà họ đóng góp cho ngân hàng.

\section{Hội nhập trong tổ chức}

"Hội nhập trong tổ chức" có mức độ ảnh hưởng thứ năm đến sự gắn kết của nhân viên. Trong tổ chức, mối quan hệ được thể hiện giữa đồng nghiệp với nhau, giữa cấp dưới với cấp trên. Những mối quan hệ này tác động mạnh mẽ đến mức độ thỏa mãn trong công việc và sự gắn kết với tổ chức. Ngân hàng nên tạo được môi trường làm việc hòa đồng, cởi mở và thân thiện bởi vì môi trường giao tiếp 
nội bộ đóng vai trò rất quan trọng, nó giúp ngân hàng hạn chế những xung đột xảy ra trong tổ chức và góp phần gia tăng tinh thần đồng đội. Ngoài ra, nhà quản trị cần tạo điều kiện để nhân viên trong ngân hàng xích lại gần nhau hơn thông qua cách sắp xếp không gian làm việc, khuyến khích mọi người ăn trưa cùng nhau, tổ chức sinh nhật chung cho nhân viên. Hơn nữa, cần phải hạn chế được rào cản quyền lực, tạo môi trường thân thiện, cởi mở; quá trình trao đổi thông tin thông suốt, nhân viên có đầy đủ thông tin cần thiết để thực hiện công việc; khi gặp vấn đề khúc mắc, người lao động có thể bày tỏ quan điểm, ý kiến với quản lý để tìm được hướng khắc phục.

\section{Quy tắc trong tổ chức}

"Quy tắc trong tổ chức" có mức độ ảnh hưởng yếu nhất đến sự gắn kết của nhân viên. Nhà quản trị cần xây dựng những chính sách, nội quy rõ ràng, minh bạch và công khai. Những chính sách này thể hiện sự tôn trọng quyền tự do, sự khác biệt của mỗi cá nhân; tạo được môi trường làm việc hòa đồng, không có sự kì thị vùng miền, tiếng nói, tôn giáo.... Ngân hàng nên xây dựng quy định rõ ràng về việc người lao động được quyền tham gia, đóng góp ý kiến vào những quyết định ảnh hưởng đến bản thân họ, đến cộng đồng trong công việc mà họ phụ trách. Ngoài ra, tất cả những chính sách, nội quy của ngân hàng phải được truyền đạt đến tất cả nhân viên kể từ khi họ bắt đầu tham gia vào ngân hàng, đảm bảo người lao động hiểu rõ quyền lợi và nghĩa vụ của mình.

\subsection{Các hạn chế của nghiên cứu và huớng nghiên cứu tiếp theo}

Mặc dù đề tài đã giải quyết xong mục tiêu nghiên cứu đã đề ra, nhưng vẫn còn một số hạn chế như sau: Thứ nhất, nghiên cứu chỉ được thực hiện với các đối tượng nghiên cứu tại ngân hàng $\mathrm{ACB} \mathrm{Tp}$. $\mathrm{HCM}$ với phương pháp lấy mẫu thuận tiện. Thư hai, nghiên cứu chỉ xem xét tác động nói chung của toàn bộ mẫu thu thập và chưa thực hiện phân tích sự khác biệt giữa các đối tượng khác nhau giữa các nhóm nhân viên như nhân viên văn phòng, nhân viên tín dụng, nhân viên dự án... Thư $b a$, chỉ nghiên cứu yếu tố gắn kết tình cảm, chưa lưu ý đến gắn bó bắt buộc, gắn bó quy chuẩn (Meyer và Allen, 1991). Đây là gợi ý cho các nghiên cứu tiếp theo. 


\section{TÀI LIẸU THAM KHẢO}

1. Asgari, M. H., \& Dadashi, M. A. (2011). Determining the Relationship Between Quality of Work Life (QWL) and Organizational Commitment of Melli Bank Staff in West Domain of Mazandaran in 2009-2010, Australian Journal of Basic and Applied Sciences, 5, pp. $682-687$.

2. Asgari, M. H., Nojbaee, S S., \& Rahnama, O. (2012). The Relationship between Quality of Work Life and Performance of Tonekabon Guidance Schools Teachers, Journal of Basic and Applied Scientific Research, 2, pp. 2569-2575.

3. Bateman, T. S., \& Strasser, S. (1984). A longitudinal analysis of the antecedents of organizationa commitment, Academy of Management Journal, 27, 1, pp. 95-112.

4. Daud, N. (2010). Investigating the Relationship between Quality of Work Life and Organizational Commitment amongst Employees in Malaysian Firms, International Journal of Business and Management, 5, 10, pp. 75 - 82.

5. Gani, A. (1993). Quality of Work Life (QWL) in a State Setting: Findings of an Empirical Study, The Indian Journal of Labour Economics, 36, pp. 817 - 823.

6. Giao, H. N. K., \& Vuong, B. N. (2016). Ảnh hưởng của các yếu tố văn hóa doanh nghiệp đến sự gắn bó của nhân viên với tổ chức tại Công ty $\mathrm{CP} C \mathrm{CMC}$ Telecom Thành Phố Hồ Chí Minh, Tạp chí Kinh tế - Kỹ thuật, 13, 1, pp. 87-101.

7. Kanten, S., Sadullah, O. (2012). An Empirical Research on Relationship Quality of Work Life and Work Engagement, Procedia - Social and Behavioral Sciences, 62, pp. 360-366.

8. Martel, J. \& Dupuis G. (2006). Quality of Work Life: Theoretical and Methodological Problems, and Presentation of a New Model and Measuring Instrument, Social Indicators Research, 77, 333-368.

9. Meyer, J. P., \& Allen, N. J. (1991), A Tree-component conceptualization of organizational commitment, Human Resource Management Review, 1, pp. 61-89.

10. Robbins, S., P. (1989). Organizational behavior: Concepts, controversies and applications. Englewood Cliffs, NJ: Prentice Hall.

11. Walton R., E. (1974). Criteria for Quality of Working Life, The Quality of Working Life, 1, pp. 91 - 104.

* Ngày nhận bài: 22/3/2017. Ngày biên tập xong: 31/3/2017. Ngày duyệt đăng: 04/4/2017 